\title{
Techniques for Minimizing and Estimating Post-Earthquake Fire Losses
}

\author{
CRAIG VAN ANNE
}

Hartford Steam Boiler Inspection and Insurance Co.

Walnut Creek, California 94598, USA

\section{RONALD P. GALLAGHER}

R. P. Gallagher Associates, Inc.

San Francisco, California 94106, USA

\section{ABSTRACT}

The state of the art of earthquake and fire protection engineering have advanced to the point where it is now possible to identify and, in many instances, mitigate sources of post-earthquake fire. A rapid and a detailed technique can be used to identify these hazards in industrial facilities. A probabilistic engineering method can be used to estimate the fire safety of a plant. Carried further, this method can be used to predict the annual loss from earthquake-induced fires.

\section{INTRODUCTION}

While post-earthquake fires have caused major conflagrations, for example following the 1906 San Francisco and 1923 Tokyo events (Ref. 1), the more typical case affects only a single facility or a relatively small number of adjacent racilities. Aside from the possibility of conflagration or fire from an acjecent property, some of the principal causes of postevent fire include :

- Failure in process equipment

- Failure or leakage of containers or lines holdine flammable materials or hot gases

- Failure in gas or electrical equipment

- Toppling of stored materials

- Loss of function of the fire protection system

Collapse of structures can also lead to fire; however, if this has happened, the facility is already heavily damaged. Hence, the emphasis in this paper is on equipment and contents.

\section{EARTHQUAKE VULNERABILITY ASSESSMENT AND MITIGATTON}

\section{Earthquake Performance of Equipment}

Earthquake damage to equipment has basically come from two sources: (1) lack of inherent ruggedness in the equipment itself and (2) lack of sufficient anchorage to prevent sliding or overturning (Ref. 2). The latter can result in damage or severing of attached piping, conduits, control wirine, and duct work.

Rugged equipment is equipment that will not fail if it is properly anchored (to the floor, wall, etc.). Examples of equipment that has 
consistently demonstrated ruggedness in earthquakes includes diesel generators, motor control centers, motors, pumps, mild steel piping with welded joints, wall-mounted electrical panels, switchgear, small steel tanks and vessels, and many boilers. While there have been occasional exceptions, generally, equipment of this type has not failed even under extremely strong shaking, provided it is properly anchored. Other equipment, such as delicate laboratory apparatus and porcelain-supported electrical equipment, has often experienced total and sometimes spectacular failure.

The usual mode of mechanical and electrical equipment failure or damage results from insufficient or inadequate anchorage (Figure 1). Occasionally, equipment is also damaged by being struck by other equipment that either was unanchored or had torn loose from its anchorage. Large unanchored boilers in the mechanical building of the Olive View Hospital slid several feet during the 1971 San Fernando earthquake (Ref. 2). These severely damaged some nearby HVAC control units. While the examples cited did not lead to post-event fire, they are indicative of the movement of unanchored equipment under strong ground shaking. Lack of anchorage, not surprisingly, is easily identified in field inspections.

\section{Identifying Seismic Hazards - Rapid Technique}

One technique, which has found increasing use, is the walk-down inspection procedure. This involves the assessment and rating of each item by a one- or two-person team of engineers experienced with seismic design of equipment, with the two-person team preferred. Each item is visually inspected for both overall seismic ruggedness and seismic anchorage and is rated as having a high $(H)$, moderate $(M)$, or low ( $L$ ) vulnerability. This is done on the basis of visual observation and engineering judgment, and no calculations are performed or reviewed.

Use of this procedure allows for the rapid assessment of complex facilities. Results for an actual inspection are given in Table 1 . This particular example is for the fire pump room of a 12-year-old facility in San Francisco, California, having over $\$ 150$ million in data processing equipment. Emergency power is provided by a skid-nounted diesel engine. Note, however, that the starting system (batteries and racks) and sustaining system (day tank) are unanchored. Because of this, the fire protection system in this building is very much at risk.

TABLE 1. Results of visual vulnerability assessment of fire protection equipment

\begin{tabular}{|c|c|c|c|c|c|}
\hline \\
\hline & Fire Pump Room & H & $\underline{M}$ & L & Comments \\
\hline & 8,300 gal. water tank & & & $\bar{X}$ & $\begin{array}{l}\text { Nuts on anchor bolts loose; these } \\
\text { should be tightened. }\end{array}$ \\
\hline 2. & Diesel pump unit & & & $x$ & Anchored. \\
\hline 3. & Battery rack for diesel & $\mathrm{X}$ & & & Rack not anchored to floor. \\
\hline & Batteries & $\mathrm{X}$ & & & Batteries not secure to rack. \\
\hline & Day tank for diesel & $\mathrm{X}$ & & & No longitudinal restraint. \\
\hline & Fuel pump for diesel & & & $\mathrm{X}$ & Anchored. \\
\hline & Battery charger & & & $\mathrm{X}$ & Anchored. \\
\hline & Motor starter for diesel & & & $\mathrm{X}$ & Anchored. \\
\hline & Electric motor pump & & & $\mathrm{X}$ & Anchored. \\
\hline 10 & Fire pump controller & & $\mathrm{X}$ & & $\begin{array}{l}\text { Marginally restrained, suggest } \\
\text { anchor at top. }\end{array}$ \\
\hline
\end{tabular}


A crucial element of this rapid technique, and that of the detailed procedure described below, is to conduct the inspection with the assistance of a person familiar with the facility and how its systems operate and interrelate. The fire protection engineer must be heavily involved in this process so that the potential ignition sources and scenarios are identified and so that the facility's fire protection system is completely identified for inspection by the earthquake engineer.

\section{Identifying Seismic Hazards - Detailed and Systematic Approach}

The rapid technique described above is very useful in sizing up the seismic vulnerability of an existing facility, but one must go further to deal with the actual hazards. The best and the most thorough approach for reviewing the possibility of post-earthquake fire is a detailed evaluation of the facility, particularly such things as equipment, tanks, and piping.

A state-of-the-art assessment normally involves identification of the active earthquake faults in the vicinity of the site and an assessment of the level of ground shaking possible in some future event (Figure 2). A design shaking level, typically an acceleration response spectrum anchored to some level of PGA (peak ground acceleration) must be selected, and the equipment evaluated against this input motion level. Evaluation can be done using calculations, shaking test data, or earthquake experience data. Alternatively, where the seismic codes are good, the evaluation may be to the local seismic code.

Eventually, regardless of the evaluation procedure used, demand is compared with the capacity of each item, and in this systematic way, deficient items are identified for remedial strengthening. It is particularly important to review ducts, exhaust pipes, flammable material containers, piping, etc., for seismic adequacy, particularly supports. Most failures in these items have been a result of support failures, and relative movement between supports is often caused by differential movements in buildings or between buildings and the equipment to which the piping is attached.

Although, as previously mentioned, buildings and structures are not a main emphasis of this paper, it should be noted that any detailed evaluation program should include consideration of buildings and structures whose earthquake failure can lead to post-event fire. Except for obviously very weak or very strong buildings, it is usually not possible to assess a structure's probable earthquake performance without resorting to detailed structural calculations.

\section{Mitigative Measures}

Once the various hazards have been identified, they must be eliminated as sources of ignition. This can often be accomplished by remedial strengthening measures, particularly for unanchored equipment for which the addition of anchorage or bracing can eliminate, or at the very least greatly reduce, the possibility of damage.

\section{FIRE HAZARD EVALUATION}

After identification of the ignition sources and an evaluation of the 
facility's potential for shaking damage, the probable fire loss scenario can be determined. In a general sense, the method given herein can take into account the unique seismic exposure of each site and the specific earthquake and fire-resistive characteristics of the facility. However, to illustrate the basic methodology, a greatly simplified example has been chosen. The use and emphasis of any procedure will have to be tailored to the unique concerns and objectives of the user.

As an example, a medium-size electrical generation facility has been selected. Fire losses can be thought of as resulting from either (1) structural failures leading to fire (i.e., broken lube oil line) or (2) failures in the fire protection system leading to an inability to control a post-earthquake fire. For this example, three fire scenarios have been identified:

1. Building collapse on a tank holding a flammable material (building).

2. Rupture of the turbine generator ( $T-G$ ) lube oil line (Iine)

3. Rupture of an oil storage tank (tank)

Each of these three soenarios has a fragility (i.e., there is some level of ground shaking that will result in enough damage for a fire to be caused). Figure 3 shows some hypothetical fragilities for each ignition source. For example, the fragility of the tank is such that, at a 8 -level of $0.4 \mathrm{~g}$, it is estimated that the probability of sustaining erough damage to cause ignition is $100 \%$. At 0.28 and less, there is assumed little or no probability of ignition, and a zero probability is assigned. Between $0.2 \mathrm{~g}$ and $0.4 \mathrm{~g}$, an engineering approximation is made, and a straight-line relationship assumed. For the lube oil line, damage that would result in a $100 \%$ probability of ignition is estimated to occur at a sround shaking level of $0.3 \mathrm{~g}$ and higher.

Using vulnerability information (developed from the walk-down inspection and detailed evaluation), the large-loss fire potential resulting from earthquake-initiated ignition can be estimated by an engineering method developed for estimating the fire safety of a building (Ref. 3). This engineering method can be tailored to evaluate specific categories of facilities and to incorporate varying types of input. The result of this evaluation yields a probability for a fire being limited (controlled) to the study area. A simplified structure of this method is shown in Figure 4. Since these events are mutually exclusive, a cumulative probability results as L, limitation (control) of the fire. For the purpose of this paper, fire control is defined as successful operation of the protection system such that further damage is halted.

The network of Figure 4 specifically evaluates the potential of the status quo to control a fire, regardless of whether the fire is postearthquake or not. This evaluation considers the type of fire expected, i.e., combustibility of available fuels $(H)$ and the determined effectiveness of automatic (A) and manual fire-fighting response (M). Each of the major elements of Figure 4 consists of detailed sub-networks that result in evaluations of $\mathrm{H}, \mathrm{A}$, and $\mathrm{M}$.

A T-G operates at steam temperatures of $1000 \mathrm{~F}$. As a result of shaking damage, lubricating oil (flash point $=300$ F) would come into contact with hot surfaces and immediately ignite a three-dimensional oil spray fire.

Under 0.38 earthquake motions, the potential for lube oil system piping to break ("Iine" in Figure 3) and thus become a fuel source is evaluated 
as 1.0 ; ignition is assumed inevitable as a worst-case scenario, i.e., $P(I G)=1.0$. The precursive probabilities can be generated from statistical, deterministic, and expert-based subjective methods of evaluation (Refs. 4 and 5). A seismic evaluation has determined that the plant site has the potential to have 0.38 motions with a probability of occurrence per year of 0.01 . Potential earthquake damage sustained by critical systems is eval-uated by a combination of a walk-down inspection and detailed evaluation.

Resulting from the same earthquake, off-site fire protection supplies (public water system) and on-site supplies (fire water tank and private yard distribution mains) may sustain damage resulting in a loss of service. This potential is evaluated as:

$P(\underline{S M})=1-P(S M)=1-[P(S) \times P(S I) \times P(A A)]$

Likewise this evaluation considers the likelihood of the availability of fire protection system hardware and the level of system performance. Table 2 lists the nomenclature used in these calculations.

The effects of shock damage have been evaluated on the facility in general. The fire protection system expected to respond to a postearthquake fire would likewise need to be evaluated. A usual form of fire protection for a $T-G$ assembly is a fixed water spray system designed to deluge bearings, ojl lines, supply equipment, and lube oil reservoirs. Lubricating oil is used in large quantities under pressure to maintain the rotation of the T-G under a controlled coastdown, and thus the ojl is the element requiring protection. A supply of this oil must be maintained any time the $T-G$ is rotating.

The probability of successful manual fire fighting is considered 0.0 in light of post-earthquake conditions. In the typical situation, of - site public assistance is unlikely because of the expected heavy demands placed on fire departments involving not only fires but also structural damage, search and rescue, hazardous material incidents, and medical aid (Ref. 6). On-site assistance will be minimal during the initial post-earthquake period because of confusion, emergency operational demands, and a need to furnish immediate medical aid to those injured. Fixed automatic fire protection systems will probably have to serve until on-site aid is practical. Controlling the fire in the initial fire stage will be critical to minimizing damage.

\section{LOSS ESTIMATION}

Further calculations like those above would generate a probabilistic assessment to estimate event and expected annual fire losses in a one-year period, using the procedure shown in Figure 5 (adapted from Ref. 7). This is a very simplified example, chosen only to illustrate the basic approach. In this example, there is a 0.10 probability of an earthquake in a one-year period.

If an earthquake occurs, it is assumed that ground motion intensity can be only one of two levels: $0.1 \mathrm{~g}$ and $0.3 \mathrm{~g}$. The probability of $0.3 \mathrm{~g}$ is also 0.1 , and therefore the probability of a 0.38 earthquake in a given year is $0.1 \times 0.1=0.01$. At $0.1 \mathrm{~g}$, review of the fragility curves (Figure 3 ) shows no damage, and thus no ignition occurs. At $0.3 \mathrm{~g}$, the building will experience no damage, but the line and the tank will sustain enough damage 
TABLE 2. Probability network nomenclature

EB: Established burning - the point at which incipient fire as a threat is reached.

I: Self-extinguishment of fire occurs.

A: Automatic suppression is successful.

M: Manual fire fighting is successful.

I.: Fire control is achieved.

S: Post-earthquake supply of the extinguishing agent is maintained.

SI: Post-earthquake operation of fire protection hardware is maintained.

AA: Post-earthquake ability of fire protection system to provide extinguishing agent design pressure and quantity is maintained.

SM: Seismic movement does not impair fire protection system.

FA: Seismic movement does not cause release of combustibles.

IG: Ignition of fuel ocours

EF: Post-earthquake fire is controlled.

NOTE: The complement of any event is the opposite of that event; $P(X)+P(\underline{X})=1.0$

to result in ignition. The line has a 1.00 probability of ignition resulting in a post-earthquake fire. The tank has a 0.50 probability of ignition. This number results in the expected annual loss estimate shown in Figure 5. Potential losses to the T-G assembly from a fire have been estimated at $\$ 50,000$ in the case of a controlled fire, and $\$ 5,000,000$ in an uncontrolled fire. The term "control" must be carefully considered because it is a relative term that must be defined in view of a loss control environment, as was done earlier.

The expected event loss from a major earthquake for the $\mathrm{T}-\mathrm{G}$ assembly can be calculated as follows:

Uncontrolled Fire Loss $=(0.79) \times(0.40) \times \$ 5,000,000=\$ 1,896,000$

Controlled Fire Loss $=(0.79) \times(1-0.40) \times \$ 50,000=\$ 23,700$

Fron Figure 5, it has been estimated that the probability of a major earthquake is $0.1 \times 0.1=0.01$. Therefore the expected annual loss from this major earthquake for the T-G assembly would be:

Uncontrolled Fire $=.10 \times .10 \times .79 \times .40 \times \$ 5,000,000=\$ 15,800$

Controlled Fire $=.10 \times .10 \times .79 \times(1-0.40) \times \$ 50,000=\$ 237$

Remedial mitigative measures taken to improve seismic resistance can dranatically affect the outcome of a post-earthquake fire. The installation of a concrete ring-wall around the fire water tank of this electrical. enerating station can eliminate differential movement between the tank and the supply piping embedded in the ground. This measure will significantly increase the probability that a fire protection water supply source would be intact after the earthquake.

In this manner the relative benefit of various remedial mitigative measures to improve seismic resistance can be evaluated. In the same manner, fire protection alternatives can be evaluated. In more complex real-world situations, there are many items to consider and a much larger number of ground motion possibilities. However, it is possible to readily develop similar information for the generalized case. This would be developed from the seismic hazard curve for the site (similar to Fig. 2) and the fragility curve for each identified fire scenario (similar to Fig. 3 ). 


\section{DISCUSSION AND SUMMARY}

The question needing to be answered in determining the damage potential due to an earthquake is what Ioss can be expected and how will it affect the ability to continue operations. With this knowledge, the traditional avenues of risk management can be taken. Once a risk is known, it can be managed by one or more of the following ways:

1. Loss transfer - transfer the cost of recovery to another party

2. Loss absorption - the cost of a loss is absorbed as a business expense

3. Loss reduction - taking actions to reduce the frequency and severity of possible losses.

Usually the form of risk management chosen is a combination of all three options. The results of the earthquake vulnerability and fire loss studies presented in this paper are intended for use in supporting the decision process on how the three above-nentioned options should be implemented. This paper has (1) presented concepts to identify and evaluate post-earthquake fire sources (i.e., walk-down inspections and detailed evaluations); (2) identified mitigative measures (i.e., remedial strengthening); and (3) addressed estimation of expected annual loss incurred from post-earthquake fire. For the latter, results are shown in a decision tree format. Also, a procedure for developing the decision tree probabilities of post-earthquake fire control is given. A relative comparison of the effectiveness of seismic mitigative measures and fire protection systems has been illustrated. It should be noted, however, that these are intended to address a single facility although the techniques presented can be further generalized to consider a cluster of facilities.

\section{REFERENCES}

1. Steinbrugge, K. V., Earthquakes, Volcanos, and Tsunamis: An Anatomy of Hazards, Skandia America Group, New York, N.Y., 1982.

2. Sharpe, R. I., and Gallagher, R. P., "Needed: Seismic Design of Mechanical and Electrical Equipment," Building Standards, Intemational Conference of Building Officials, Whittier, CA, September 1972.

3. Fitzgerald, W. R., "Risk Analysis Using the Engineering Method for Building Analysis," Worcester Polytechnic Institute, 1984.

4. Van Anne, C., "Evaluation of the Risk Problem and the Selection of the Optimum Rj.sk Management Solution," First International Symposium on Fire Safety Science, National Bureau of Standards, Gaithersburg, Maryland, October 1985.

5. Van Anne, C., "Managing Firesafety Problems Through Decision Analysis to Evaluate Firesafety Hazards," National Fire Protection Association Annual Meeting, Atlanta, Georgia, 1986.

6. Scawthorn, C., "Fire Following Earthquake," First Internationa1 Symposium on Fire Safety Science, National Bureau of Standards, Gaithersburg, Maryland, October 1985.

7. Benjamin, J. R., "Risk Management," Chapter 10 of Seismic-Safety Guide, Lawrence Berkeley Laboratory, University of California, Berkeley, September 1983. 


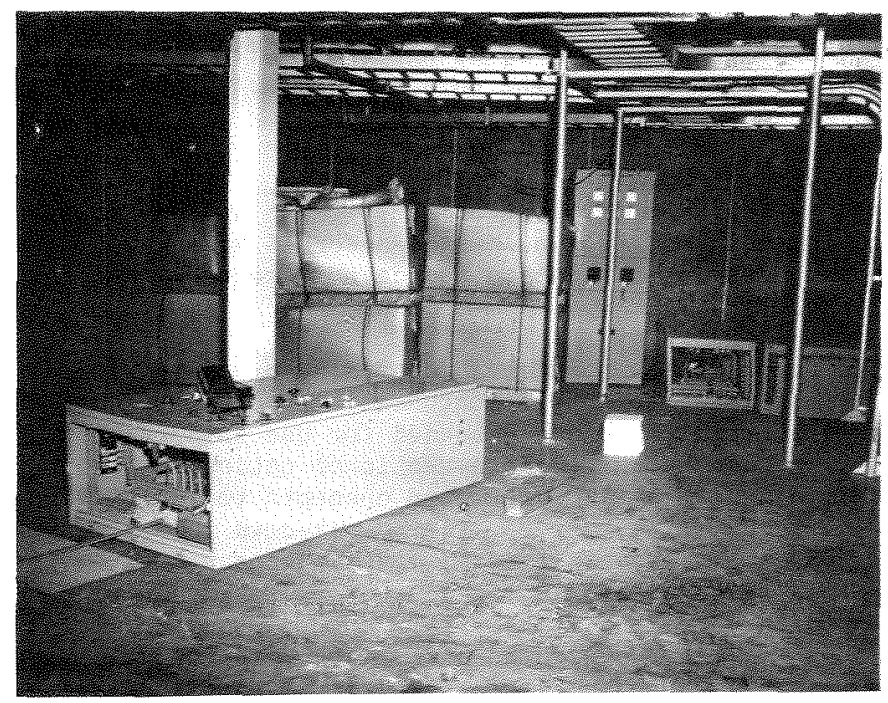

A. Overturned electrical panel

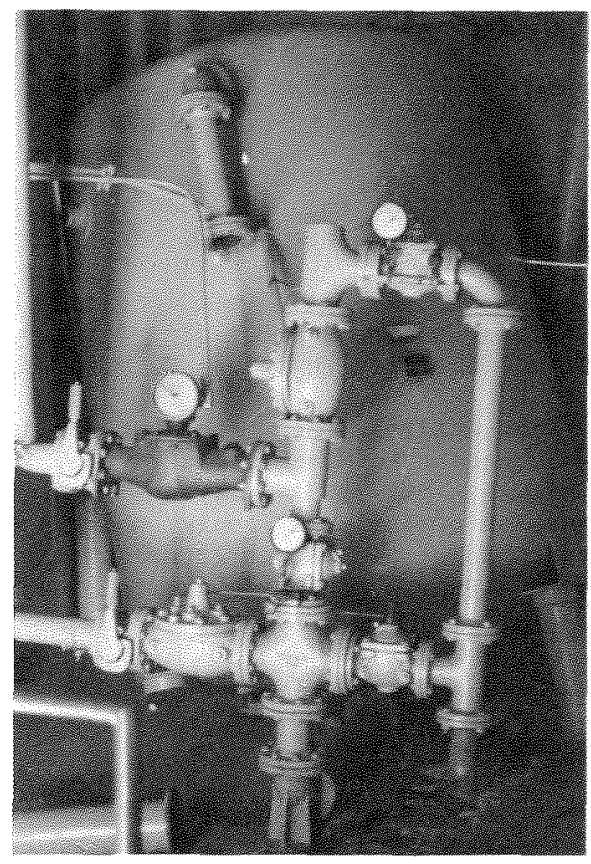

B. Unanchored water softener tank

FIGURE 1. Equipment failures from the 1971 San Fernando earthquake caused by lack of anchorage. 


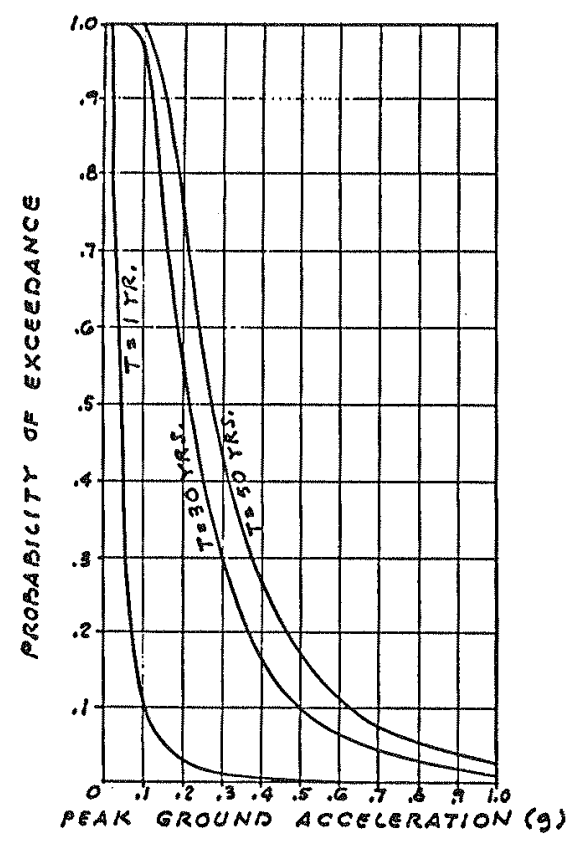

FIGURE 2. Seismic hazard curve for site in San Francisco Bay Area

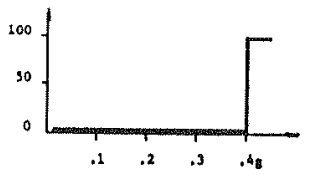

BUILDTMG COLLAPSB

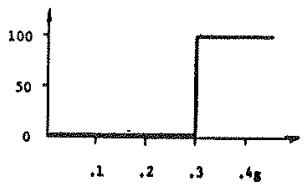

LUBE OIL LINE EREAK

OF IGAITION

(x)
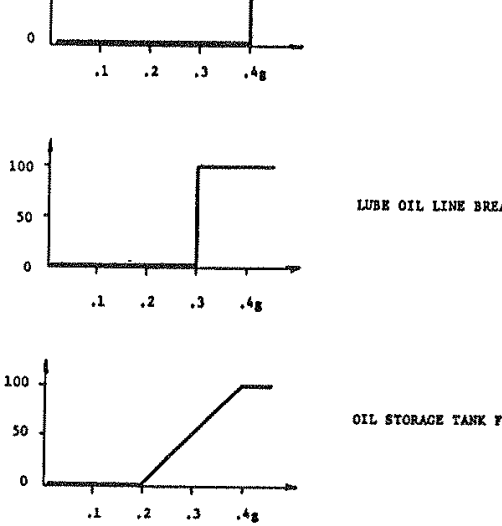

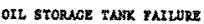

FIGURE 3. Probability of ignition as a function of peak ground acceleration 


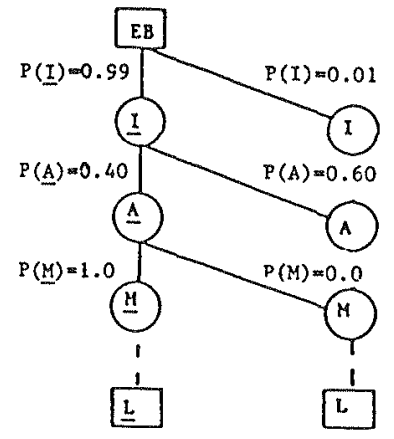

FIGURE 4. The engineering method probability network for evaluating fire.

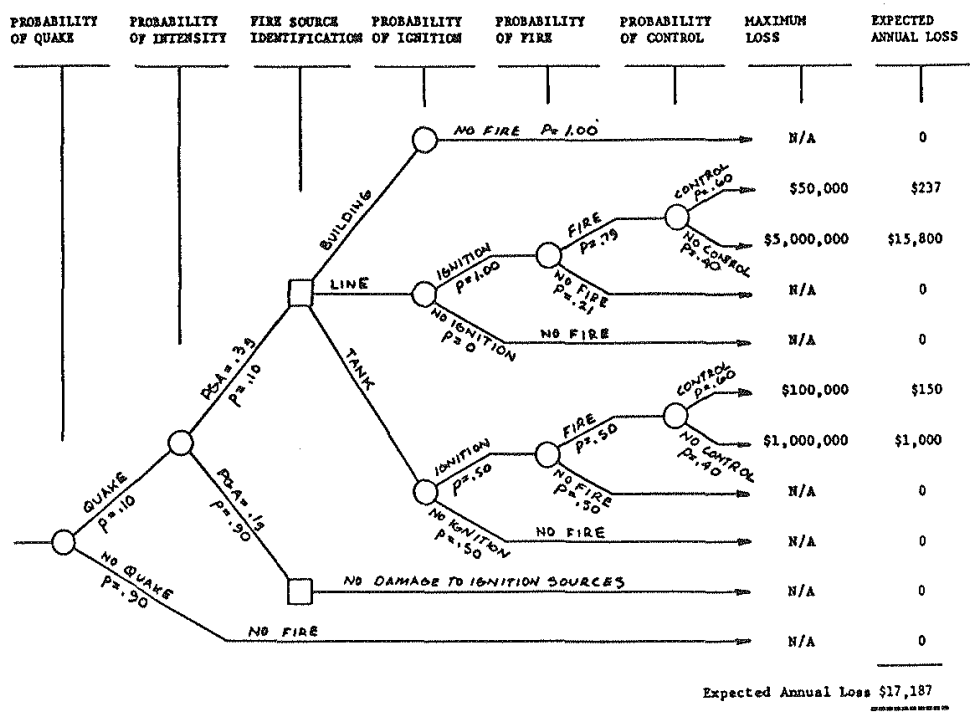

FIGURE 5. Expected annual post-earthquake fire loss. 